\title{
Ethanol Facilitates Glutamatergic Transmission to Dopamine Neurons in the Ventral Tegmental Area
}

\author{
Cheng Xiao ${ }^{1,2}$, Xuesi Max Shao ${ }^{3}$, M Foster Olive ${ }^{4}$, William C Griffin III ${ }^{4}$, Ke-Yong Li ${ }^{1,2}$, Kresimir Krnjevićc \\ Chunyi Zhou ${ }^{1,2}$ and Jiang-Hong Ye*, $\mathrm{e}^{*, 2}$ \\ 'Department of Anesthesiology, University of Medicine and Dentistry of New Jersey, New Jersey Medical School, Newark, NJ, USA; ${ }^{2}$ Department \\ of Physiology and Pharmacology, University of Medicine and Dentistry of New Jersey, New Jersey Medical School, Newark, NJ, USA; ${ }^{3}$ Department \\ of Neurobiology, David Geffen School of Medicine at UCLA, Los Angeles, CA, USA; ${ }^{4}$ Department of Psychiatry and Behavioral Sciences, Center for \\ Drug and Alcohol Programs, Medical University of South Carolina, Charleston, SC, USA; ${ }^{5}$ Department of Physiology, McGill University, Montréal, \\ QC, Canada
}

\begin{abstract}
The cellular mechanisms underlying alcohol addiction are poorly understood. In several brain areas, ethanol depresses glutamatergic excitatory transmission, but how it affects excitatory synapses on dopamine neurons of the ventral tegmental area (VTA), a crucial site for the development of drug addiction, is not known. We report here that in midbrain slices from rats, clinically relevant concentrations of ethanol ( $10-80 \mathrm{mM}$ ) increase the amplitude of evoked EPSCs and reduce their paired-pulse ratio in dopamine neurons in the VTA. The EPSCs were mediated by glutamate $\alpha$-amino-3-hydroxy-5-methylisoxazole-4-propionic acid (AMPA) receptors. In addition, ethanol increases the frequency but not the amplitude of spontaneous EPSCs. Furthermore, ethanol increases extracellular glutamate levels in the VTA of midbrain slices. The effects of ethanol are mimicked by SKF 38393, a dopamine D, receptor agonist, and by GBR I2935, a dopamine reuptake inhibitor, and they are blocked by SKF 83566, a D, antagonist, or by reserpine, which depletes dopamine stores. The enhancement of sEPSC frequency reaches a peak with $40 \mathrm{mM}$ ethanol and declines with concentrations $\geqslant 80 \mathrm{mM}$ ethanol, which is quite likely a result of $D_{2}$ receptor activation as raclopride, a $D_{2}$ receptor blocker, significantly enhanced $80 \mathrm{mM}$ ethanol-induced enhancement of sEPSCs. Finally, 6, 7-dinitroquinoxaline-2, 3-dione (DNQX), an AMPA receptor antagonist, attenuates ethanol-induced excitation of VTA DA neurons. We therefore conclude that, acting via presynaptic D, receptors, ethanol at low concentrations increases glutamate release in the VTA, thus raising somatodendritic dopamine release, which further activates the presynaptic $D$, receptors. Enhancement of this positive feedback loop may significantly contribute to the development of alcohol addiction.

Neuropsychopharmacology (2009) 34, 307-318; doi: I 0.1038/npp.2008.99; published online 2 July 2008
\end{abstract}

Keywords: mesolimbic system; addiction; alcohol; glutamate; $D_{1}$ and $D_{2}$ receptors; raclopride

\section{INTRODUCTION}

Numerous studies have associated the mesolimbic dopaminergic (DA) system, originating from the ventral tegmental area (VTA), with ethanol addiction. For instance, (1) ethanol consumption is reduced by the administration of dopamine antagonists (Samson et al, 1993; Price and Middaugh, 2004) or agonists ( $\mathrm{Ng}$ and George, 1994), or by the genetic deletion of dopamine $D_{1}$ receptors $\left(D_{1} R\right)$ (El-Ghundi et al, 1998); (2) pharmacological manipulations of VTA DA neuron activity alter ethanol consumption (Rassnick et al, 1993; Nowak et al, 1998); (3) ethanol

\footnotetext{
*Correspondence: DrJ-H Ye, Department of Anesthesiology, UMDNJ, New Jersey Medical School, 185 South Orange Avenue, Newark, New Jersey 07I03, USA, Tel: + I 973972 1866, Fax: + I 973972 4I72, E-mail: ye@umdnj.edu

Received 12 November 2007; revised 31 March 2008; accepted 19 May 2008
}

increases dopamine release, from both the synaptic terminals (in nucleus accumbens (NAcc)) and the somatodendritic region in the VTA (Imperato and Di Chiara, 1986; Campbell et al, 1996; Hodge et al, 1997; Ikemoto et al, 1997; Koob et al, 1998; Doyon et al, 2003, 2005); and (4) ethanol stimulates the spontaneous activity of VTA DA neurons (Imperato and Di Chiara, 1986; Brodie et al, 1990, 1999a, b; Doyon et al, 2003, 2005; Xiao et al, 2007). However, the specific mechanism by which ethanol excites VTA DA neurons has not been fully clarified.

Glutamate, the main excitatory neurotransmitter in the brain, excites VTA DA neurons (Suaud-Chagny et al, 1992). Glutamate release in the VTA can be regulated by many agents. For instance, it is increased by activating $D_{1}$ (Kalivas and Duffy, 1995) and nicotinic acetylcholine receptors (Erhardt et al, 2002), as well as receptors for corticotropinreleasing factor (Wang et al, 2005), or decreased by activating $\mathrm{GABA}_{\mathrm{B}}$, adenosine $\mathrm{A}_{1}$ (Bonci and Malenka, 1999), $\kappa$ and $\mu$ opioid (Margolis et al, 2005), $\mathrm{CB}_{1}$ 
cannabinoid (Melis et al, 2004), metabotropic glutamate, and $\mathrm{M}_{3}$ muscarinic acetylcholine (Zheng and Johnson, 2003) receptors.

Glutamatergic (GLUergic) transmission is an important mediator of behavioral changes caused by ethanol (Eckardt et al, 1998; Krystal et al, 2003). In several brain regions, ethanol inhibits NMDA and non-NMDA glutamate receptors, as well as glutamate release (Siggins et al, 2005), but in some situations, ethanol increases glutamate release (Selim and Bradberry, 1996; Dahchour et al, 2000; Roberto et al, 2004; Zhu et al, 2007). For instance, systemic administration of ethanol increases glutamate release in NAcc of lowalcohol-sensitive rats (Dahchour et al, 2000) and addictionprone Lewis rats (Selim and Bradberry, 1996). In recent studies on the central nucleus of the amygdala, acute ethanol increased glutamate release only in rats receiving chronic ethanol treatment (Roberto et al, 2004; Zhu et al, 2007). However, no information is available about the effects of ethanol on GLUergic transmission to VTA DA neurons.

Bearing in mind that genetic deletion of $D_{1}$ Rs reduces ethanol consumption (El-Ghundi et al, 1998) and that ethanol stimulates somatodendritic dopamine release, which may activate $D_{1}$ Rs expressed on GLUergic axons synapsing onto VTA DA neurons (Lu et al, 1997), we hypothesized that ethanol indirectly activates $D_{1} R s$ to potentiate GLUergic transmission in this region. To examine this possibility, we analyzed the effects of acute ethanol on EPSCs and extracellular glutamate levels in the VTA in midbrain slices.

\section{MATERIALS AND METHODS}

All procedures were approved by the Institutional Animal Care and Use Committee of the University of Medicine and Dentistry of New Jersey, in accordance with the guidelines of the National Institutes of Health (Guide for the Care and Use of Laboratory Animals), minimizing the number of animals and their suffering. Experiments were done on slices from adolescent Sprague-Dawley rats (at postnatal days 22-32).

\section{Slice Preparation}

The midbrain slices were prepared as described earlier (Ye et al, 2004, 2006). Rats were anesthetized with ketamine/ xylazine and then decapitated. Coronal midbrain slices $(250 \mu \mathrm{m}$ thick) were cut with a VF-200 slicer (Precisionary Instruments Inc., Greenville, NC) in ice-cold glycerolbased artificial cerebrospinal fluid containing (in $\mathrm{mM}$ ) 250 glycerol, $1.6 \mathrm{KCl}, 1.2 \mathrm{NaH}_{2} \mathrm{PO}_{4}, 1.2 \mathrm{MgCl}_{2}, 2.4 \mathrm{CaCl}_{2}, 25$ $\mathrm{NaHCO}_{3}$, and 11 glucose, and saturated with $95 \% \mathrm{O}_{2} / 5 \% \mathrm{CO}_{2}$ (carbogen) (Ye et al, 2006). Two slices per animal were allowed to recover for at least $1 \mathrm{~h}$ in a holding chamber at $31^{\circ} \mathrm{C}$ in carbogen-saturated standard ACSF, which has the same composition as glycerol-based artificial cerebrospinal fluid, except that glycerol was replaced by $125 \mathrm{mM} \mathrm{NaCl}$.

\section{Electrophysiological Recording}

Electrical signals were obtained in whole-cell and loose-patch cell-attached patch clamp configurations with
MultiClamp 700 A amplifiers (Molecular Devices Co., Union City, CA, USA), a Digidata 1320 A A/D converter (Molecular Devices Co.) and pCLAMP 9.2 software (Molecular Devices Co.). Data were filtered at $1 \mathrm{kHz}$ and sampled at $5 \mathrm{kHz}$. The patch electrodes had a resistance of 4-6 M $\Omega$ when filled with a pipette solution containing (in $\mathrm{mM}$ ): $135 \mathrm{~K}$ gluconate, $5 \mathrm{KCl}, 2 \mathrm{MgCl}_{2}$, 10 HEPES, $2 \mathrm{Mg}$ ATP, $0.2 \mathrm{GTP}$, and $2 \mathrm{QX}-314$. The $\mathrm{pH}$ was adjusted to 7.2 with Tris base. A single slice was transferred to a $0.4 \mathrm{ml}$ recording chamber, where it was held down by a platinum ring. Throughout the experiments, the bath was continually perfused with carbogenated ACSF $(1.5-2.0 \mathrm{ml} / \mathrm{min})$. Cells were visualized with an upright microscope (E600FN, Nikon) and near-infrared illumination.

All recordings were obtained from putative DA neurons identified by their pharmacological, physiological, and cytochemical properties. Specifically, spontaneous firing of VTA neurons was first recorded with the loose-patch cell-attached configuration. The depression of spontaneous firing by $0.2 \mu \mathrm{M}$ quinpirole, a dopamine $\mathrm{D}_{2} / \mathrm{D}_{3}$ receptor agonist, and facilitation by $1 \mu \mathrm{M}$ DAMGO, a $\mu$-opioid receptor agonist (as a result of DAMGO-induced disinhibition of inhibitory GABAergic neurons in the VTA, Figure 1c), are characteristic features of VTA DA neurons (Johnson et al, 1992; Johnson and North, 1992; Margolis et al, 2003). Further suction changed the recording to the whole-cell configuration. A prominent inward current $\left(\mathrm{I}_{h}\right)$ activated by hyperpolarizing voltage steps (between -60 and $-140 \mathrm{mV}$, Figure 1d, left panel) or a corresponding voltage sag in response to a hyperpolarizing current pulse (between -100 and $0 \mathrm{pA}$, Figure 1d, right panel) (Lacey et al, 1989) confirmed the identity of putative DA neurons.

To evoke monosynaptic EPSCs (eEPSCs), the tip of a glass-stimulating pipette, filled with $1 \mathrm{M} \mathrm{NaCl}$, was placed $50-100 \mu \mathrm{m}$ from the recorded VTA neuron. Electrical stimuli (100-200 $\mu$ s in duration) were applied at the rate of $0.05 \mathrm{~Hz}$. Near the start of the recording, an input/output curve was obtained, and the stimulation was then set to 20$30 \%$ of the maximum, an intensity that evoked stable responses with no failures. Paired eEPSCs were elicited with a pair of identical stimuli separated by an interval of $50 \mathrm{~ms}$. Series resistance was checked before and after the experiments by series resistance compensation. To measure input resistance, we applied a $5 \mathrm{mV}, 400 \mathrm{~ms}$ hyperpolarizing pulse and divided $5 \mathrm{mV}$ by the final value of the evoked current. The data were discarded if series resistance (15-30 M $\Omega$ ) or input resistance (300-500 M $\Omega$ ) changed by more than $20 \%$ during the whole-cell recording. All these experiments were done at a temperature of $33 \pm 1^{\circ} \mathrm{C}$, maintained by an automatic temperature controller (Warner Instruments, Hamden, CT).

\section{Immunocytochemistry}

The identification of VTA DA neuron by the responses to quinpirole and the expression of $I_{h}$ has been challenged (Margolis et al, 2006). Therefore, to validate the electrophysiological and pharmacological identification of DA neurons, a subset of neurons were examined immunocytochemically for tyrosine hydroxylase (TH). In these experiments, we included Alexa Fluor ${ }^{\circledR} 555$ dextran $(0.05 \%$, w/v, Invitrogen Corporation, Carlsbad, CA) in 

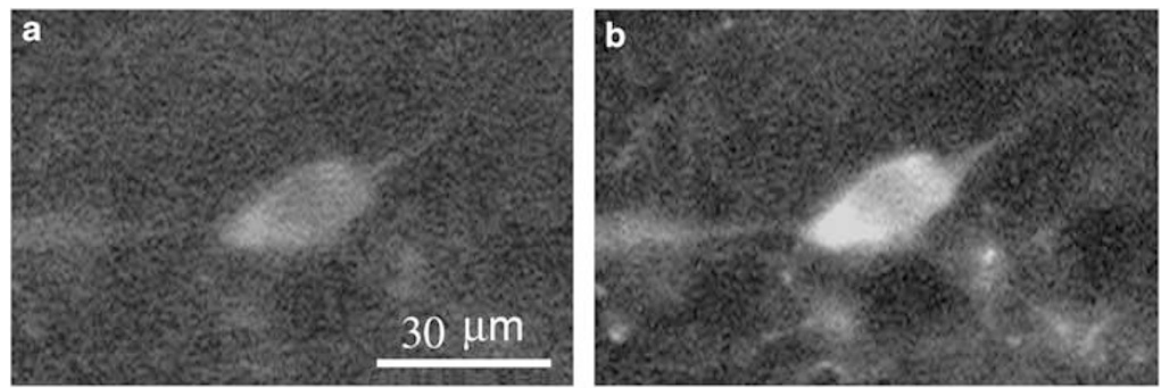

c

DAMGO

Wash
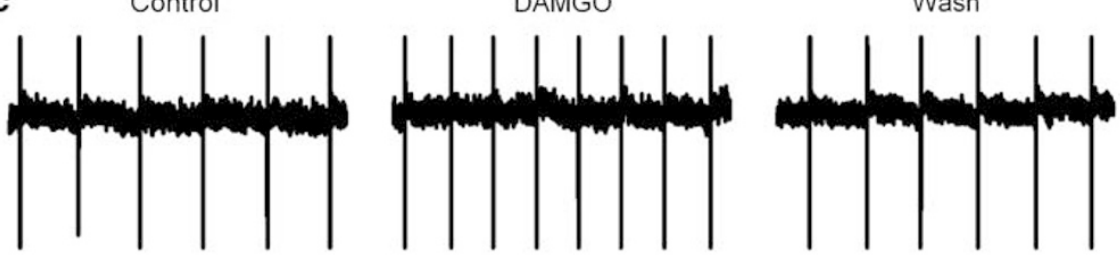

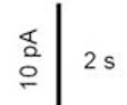
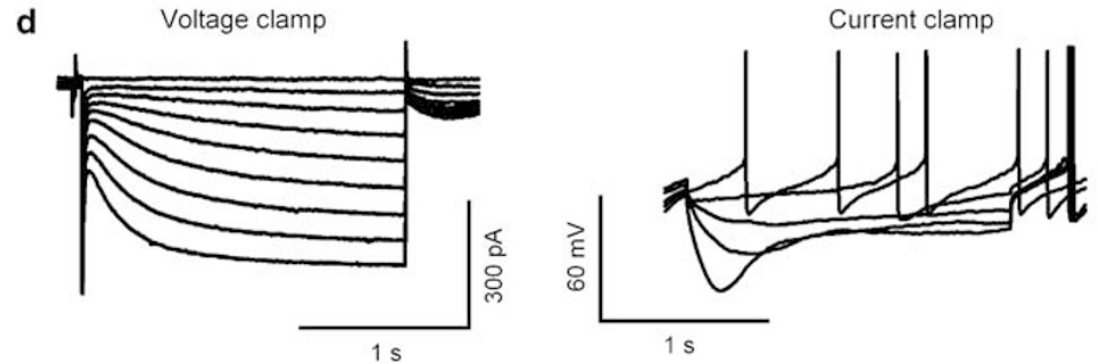

Figure I Identification of recorded neuron as VTA DA neuron. (a) Electrically recorded cell was labeled with Alexa FluoR 555 Dextran (0.05\%) released from recording pipette, yielding red fluorescence. (b) Subsequent cytochemical treatment showed that it was also TH-positive (green fluorescence. (c) Spontaneous discharge recorded in cell-attached mode was accelerated by $2 \mu M$ DAMGO. (d) Under voltage clamp, the currents induced by a series of hyperpolarizing voltage pulses show the large time-dependent inward currents ( $h_{h}$, left panel). Under current clamp, this neuron has prominent time-dependent decreases in voltage during application of rectangular hyperpolarizing currents (right panel).

the intra-pipette solution to label the recorded neurons (red fluorescence in Figure 1a). After electrical recording, to stain for tyrosine hydroxylase, the slice was fixed for $2 \mathrm{~h}$ in $4 \%$ paraformaldehyde in $\mathrm{PBS}$ at $4^{\circ} \mathrm{C}$, washed two times with cold PBS, and stored overnight at $4^{\circ} \mathrm{C}$ in PBS/ $0.1 \%$ sodium azide. It was then permeabilized for $20 \mathrm{~min}$ at $4{ }^{\circ} \mathrm{C}$ in $\mathrm{TBS} / 0.5 \%$ Triton $\mathrm{X}-100$, blocked for $1 \mathrm{~h}$ at $4^{\circ} \mathrm{C}$ in $5 \%$ donkey serum in TBS/0.1\% Triton X-100, and incubated overnight at $4{ }^{\circ} \mathrm{C}$ with a primary antibody rabbit anti-TH (Pel-Freez Biologicals, Rogers, AR, 1:100 dilution) in TBS $/ 0.1 \%$ Triton X-100 containing 5\% donkey serum. The slice was then washed three times ( 5 min each) in TBS $/ 0.1 \%$ Triton X-100, incubated for $1 \mathrm{~h}$ in secondary antibody at room temperature (Alexa Fluor 488 goat antirabbit IgG, Invitrogen Corporation, Carlsbad, CA, 1:500 dilution) in TBS/0.1\% Triton X-100 containing 5\% donkey serum, washed three times (10 min each) in TBS/0.1\% Triton X-100, and then covered with Vectashield. Slides were immediately examined on a three-color immunofluorescence microscope (Nikon Instruments Inc., Melvelle, NY). TH-positive neurons were stained green, Figure $1 b)$.
Among 16 recorded and red fluorescence-labeled neurons, $12(75 \%)$ were also TH-positive and $10(63 \%)$ were $\mathrm{I}_{\mathrm{h}}{ }^{-}$ positive (not significantly different: by Fisher's exact test, $p=0.70)$. $\mathrm{I}_{\mathrm{h}}$ was expressed in 9/12 (75\%) TH-positive neurons but not in four TH-negative neurons (significantly different: by Fisher's exact test, $p=0.019$ ). Among $10 \mathrm{I}_{\mathrm{h}}$ positive neurons, nine (90\%) were TH-positive and six $(60 \%)$ were disinhibited by DAMGO (not significantly different: by Fisher's exact test, $p=0.30$ ). All neurons (6/ 6) that were $I_{h}$-positive and disinhibited by DAMGO were TH-positive and thus highly likely to be DA neurons. This supports the notion that $\mathrm{I}_{\mathrm{h}}$ is expressed in a substantial portion, if not all, of VTA DA neurons (Johnson et al, 1992; Johnson and North, 1992; Margolis et al, 2006). In agreement with previous studies, the neurons expressing $I_{h}$ and disinhibited by $\mu$-opioid agonist were therefore very likely to be dopaminergic, because, (1) VTA GABAergic neurons have no prominent $\mathrm{I}_{\mathrm{h}}$ (Jones and Kauer, 1999) and they are inhibited by $\mu$-opioid receptor agonists (Margolis et al, 2003), and (2) in the VTA, DAMGO uniquely excites DA neurons by a mechanism of disinhibition (Margolis et al, 2003; Xiao et al, 2007). 


\section{Measurement of Glutamate in Midbrain Slices}

We measured extracellular glutamate in the VTA with a new method developed by Shao and Feldman (2007). A midbrain slice was transferred to a $1.2 \mathrm{ml}$ chamber and perfused with carbogenated ACSF (at a rate of $2 \mathrm{ml} / \mathrm{min}$ ). The VTA was visualized with an upright microscope (Axioskop 2FS, Zeiss). The tip of the sampling pipette - its inner diameter $(450-550 \mu \mathrm{m})$ approximately covering the VTA in young rats - was pressed against the surface of the slice over the VTA. Ten microliters of sample fluid was collected at the rate of $2 \mu \mathrm{l} / \mathrm{min}$ by a micro-syringe pump (UltraMicroPump II, World Precision Instruments, Sarasota, FL). A small piece of filter paper in the tip prevented entry of brain tissue into the pipette. The collected fluid was immediately frozen and kept at $-20^{\circ} \mathrm{C}$. After the samples were thawed, glutamate was measured by high performance liquid chromatography (Olive et al, 2000).

\section{Chemicals and Applications}

Bicuculline, DL-2-amino-5-phosphono-valeric acid (DLAPV), 6, 7-dinitroquinoxaline-2, 3-dione (DNQX), QX-314, reserpine hydrochloride, tetrodotoxin (TTX), [D-Ala ${ }^{2}$, $\mathrm{N}-\mathrm{Me}-\mathrm{Phe}^{4}, \mathrm{Gly}^{5}$-ol] enkephalin (DAMGO) were obtained from Sigma-Aldrich Chemical Company (St Louis, MO, USA). (-)-Quinpirole hydrochloride (QP), GBR 12935, $\mathrm{N}$-allyl-( \pm )-SKF 38393, ( \pm )-SKF 83566 were from TOCRIS Bioscience (Ellisville, MO, USA). The $1000 \times$ stock solutions were aliquoted and then stored at $-20,4^{\circ} \mathrm{C}$, or room temperature according to the catalog recommendations. Reserpine (10 mM) was dissolved in acetic acid (1/1000), APV (50 mM), and DNQX (20 mM) in $\sim 0.1 \mathrm{~N} \mathrm{NaOH}$, and other agents in deionized water. Ethanol (95\%, prepared from grain) was from Pharmco (Brookfield, CT, USA) and stored in glass bottles. Drugs at final concentration were added to the superfusate.

\section{Data Analysis}

Spontaneous excitatory postsynaptic currents (sEPSCs) and miniature EPSCs (mEPSCs) were counted and analyzed with Clampfit 9.2 (Molecular Devices Co.). They were screened automatically by 'template search.' The template was selected visually according to the rise and decay phases of sEPSCs, and the amplitude threshold was set to $5 \mathrm{pA}$. The height of evoked eEPSCs (eEPSCs) was measured with Clampfit 9.2 and was used to calculate the paired pulse ratio $\left(\mathrm{PPR}=\mathrm{EPSC}_{2} / \mathrm{EPSC}_{1}\right)$, where $\mathrm{EPSC}_{1}$ and $\mathrm{EPSC}_{2}$ were evoked by the first and second stimuli. The eEPSC amplitude, PPR, and the frequency of sEPSCs and mEPSCs during and after drug applications were normalized to their mean value during the initial control period $(>2 \mathrm{~min})$. These data were used to depict summarized time courses (10-30 s per/bin). The baseline mean values were obtained during the initial control period and the mean values, during drug application over a 1-2 min period at the peak of a drug response. Drug effects were expressed as \% change (mean \pm SEM) from pre-drug control baseline. Paired or unpaired two-tailed $t$-test evaluated the statistical significance of various drug effects (\% change from control baseline). Cumulative probability plots of the incidence of various inter-event intervals and amplitudes (for 100-1500 sEPSCs and mEPSCs), recorded in control conditions and during drug applications to the same neuron, were analyzed with the Kolmogorov-Smirnov (K-S) test. In the figures, single eEPSCs or paired eEPSCs are averages of $>10$ successive traces. Values of $p<0.05$ were considered significant.

\section{RESULTS}

\section{Ethanol Enhances Evoked EPSCs in Putative DA Neurons in VTA}

In the presence of $10 \mu \mathrm{M}$ bicuculline and at a holding potential $\left(\mathrm{V}_{\mathrm{H}}\right)$ of $-70 \mathrm{mV}$, EPSCs were evoked by a local stimulating electrode. These EPSCs were completely blocked by $20 \mu \mathrm{M}$ DNQX, indicating that they were mediated by $\alpha$-amino-3-hydroxy-5-methylisoxazole-4-propionic acid (AMPA) receptors (Figure $2 \mathrm{~b}$ ). Unexpectedly, $40 \mathrm{mM}$ ethanol enhanced the amplitude of such eEPSCs (Figure $2 \mathrm{a}_{1-2}$ ) by $33 \pm 5 \%$ (from $70 \pm 14$ to $90 \pm 17 \mathrm{pA}, n=9$; $p<0.01$, by paired $t$-test). Next, we applied pairs of stimuli (at $50 \mathrm{~ms}$ interval) to evoke paired EPSCs. As shown in Figure $2 c_{1-2}$, ethanol $(40 \mathrm{mM})$ increased the amplitude of the first EPSC of each pair but not the second, and thus decreased the paired-pulse ratio $\left(\mathrm{PPR}=\mathrm{EPSC}_{2} / \mathrm{EPSC}_{1}\right)$ by $22 \pm 3 \%$, from $1.5 \pm 0.2$ before to $1.2 \pm 0.1$ after ethanol $(n=9, p<0.01$, paired $t$-test). Changes in transmitter release generally affect the PPR (Bonci and Williams, 1997; Ye et al, 2004). These results suggest that ethanol increases presynaptic glutamate release.

Ethanol Increases the Frequency but not the Amplitude of Spontaneous EPSCs (sEPSCs) in Putative DA Neurons in VTA

We then examined sEPSCs in $10 \mu \mathrm{M}$ bicuculline at a $\mathrm{V}_{\mathrm{H}}$ of $-70 \mathrm{mV}$. Their suppression by $20 \mu \mathrm{M}$ DNQX (Figure $3 \mathrm{a}$ ) indicated that they were indeed GLUergic sEPSCs mediated by AMPA receptors. Ethanol $(40 \mathrm{mM})$ increased their frequency (Figure $3 b$ and $c$ ) by $61 \pm 11 \%$ (from $1.1 \pm 0.5$ to $1.6 \pm 0.7 \mathrm{~Hz}, n=9, p<0.01$, by paired $t$-test, Figure $3 e_{1}$ ). This is further shown in Figure $3 \mathrm{~d}_{1}$ by the sharp increase in the probability of shorter intervals between successive sEPSCs (K-S test, $p<0.01$ ). After washout of ethanol, the sEPSC frequency returned to control levels (Figure $3 \mathrm{~b}$ and c). This effect of ethanol was reproducible after washout for $>10 \mathrm{~min}$ (data not shown). However, $40 \mathrm{mM}$ ethanol did not alter sEPSC amplitudes (K-S test: $p>0.5$, Figure $3 \mathrm{~d}_{2}$ ). Figure $3 \mathrm{e}_{1}$ illustrates the dose dependence of ethanolinduced increases in sEPSC frequency: for ethanol concentrations up to $40 \mathrm{mM}$, sEPSC frequency increased progressively ( $10 \mathrm{mM}: 15 \pm 3 \%, n=7, p<0.01 ; 20 \mathrm{mM}$ : $37 \pm 4 \%$, $n=9, p<0.01 ; 40 \mathrm{mM}: 61 \pm 11 \%, n=9, p<0.01)$ but when the concentration was doubled again to $80 \mathrm{mM}$, the increase in frequency diminished to $41 \pm 5 \% \quad(n=6, p<0.01$; Figure $3 \mathrm{e}_{1}$ ). On the other hand, at all these concentrations, ethanol did not significantly alter sEPSC amplitudes, as shown by the histogram in Figure $3 \mathrm{e}_{2}(10 \mathrm{mM}: 5 \pm 6 \%, n=7$, $p=0.3 ; 20 \mathrm{mM}: 7 \pm 6 \%, n=9, p=0.18 ; 40 \mathrm{mM}: 9 \pm 9 \%$, $n=9, p=0.17 ; 80 \mathrm{mM}: 2 \pm 5 \%, n=6, p=0.47)$. These results are consistent with a presynaptic mechanism of 
a
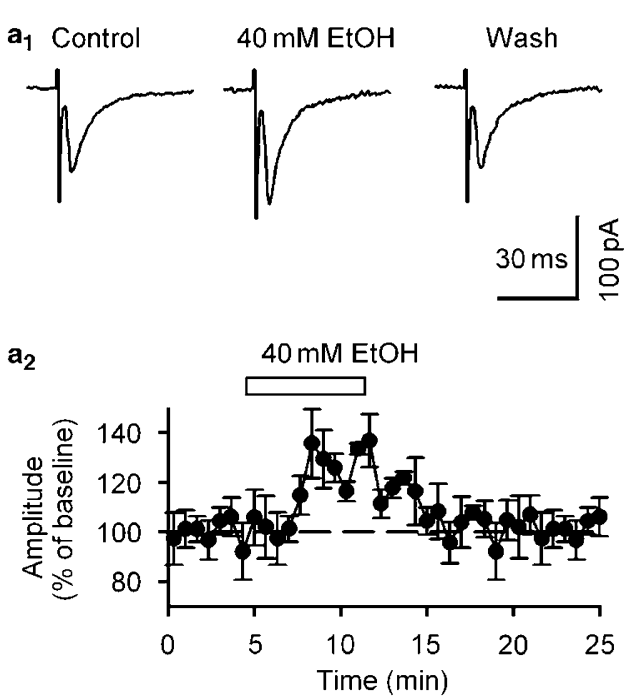

b

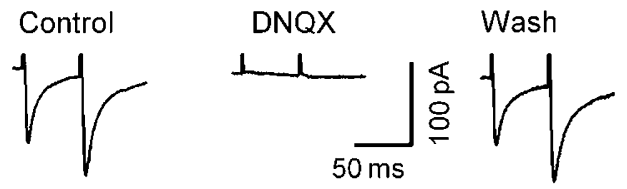

C $c_{1}$ Control $40 \mathrm{mM}$ EtOH
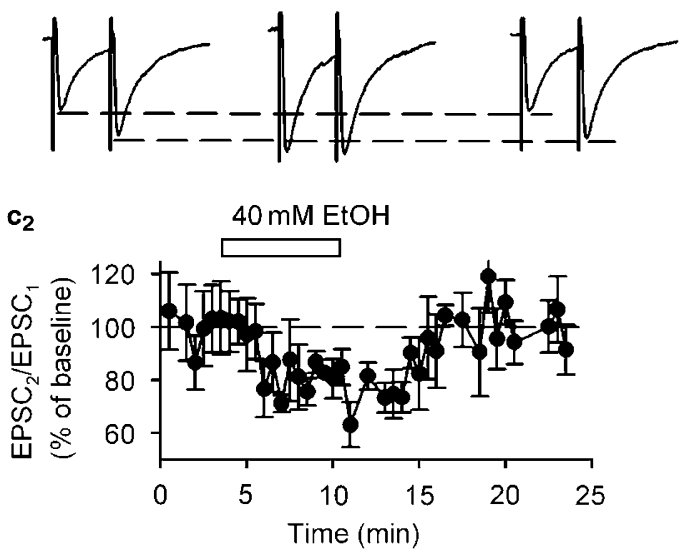

Figure 2 Ethanol enhances EPSCs evoked in putative DA neurons in midbrain slices. (a) EPSCs evoked by electrical stimulation within the VTA $\left(\mathrm{a}_{1}\right) .\left(\mathrm{a}_{2}\right)$ Time course of change in eEPSC amplitude (mean \pm SEM) induced by $40 \mathrm{mM}$ ethanol $(n=5)$. (b) Responses to paired-pulse stimulation (at $50 \mathrm{~ms}$ interval), which were completely blocked by AMPA-type glutamate antagonist DNQX $(20 \mu \mathrm{M})$. $\left(c_{1}\right)$ Ethanol significantly reduced the paired-pulse ratio. Data are averages of 10 traces. $\left(c_{2}\right)$ Time course of ethanol-induced reduction of paired-pulse facilitation (mean \pm SEM; $n=5$ ). All EPSCs were recorded at a $V_{H}$ of $-70 \mathrm{mV}$ and in the presence of $10 \mu \mathrm{M}$ bicuculline.

ethanol action, enhancing GLUergic transmission by increasing glutamate release.

\section{Ethanol does not Alter Miniature EPSCs (mEPSCs) in} Putative DA Neurons in VTA

Next, we recorded mEPSCs in the presence of tetrodotoxin (TTX, $1 \mu \mathrm{M})$ and bicuculline $(10 \mu \mathrm{M})$. Applications of TTX reduced the frequency of the spontaneous events only slightly, albeit significantly $(1.4 \pm 0.4 \mathrm{~Hz}$ in control, $1.1 \pm 0.4 \mathrm{~Hz}$ in TTX, $p<0.05, n=5$ ), but not their mean
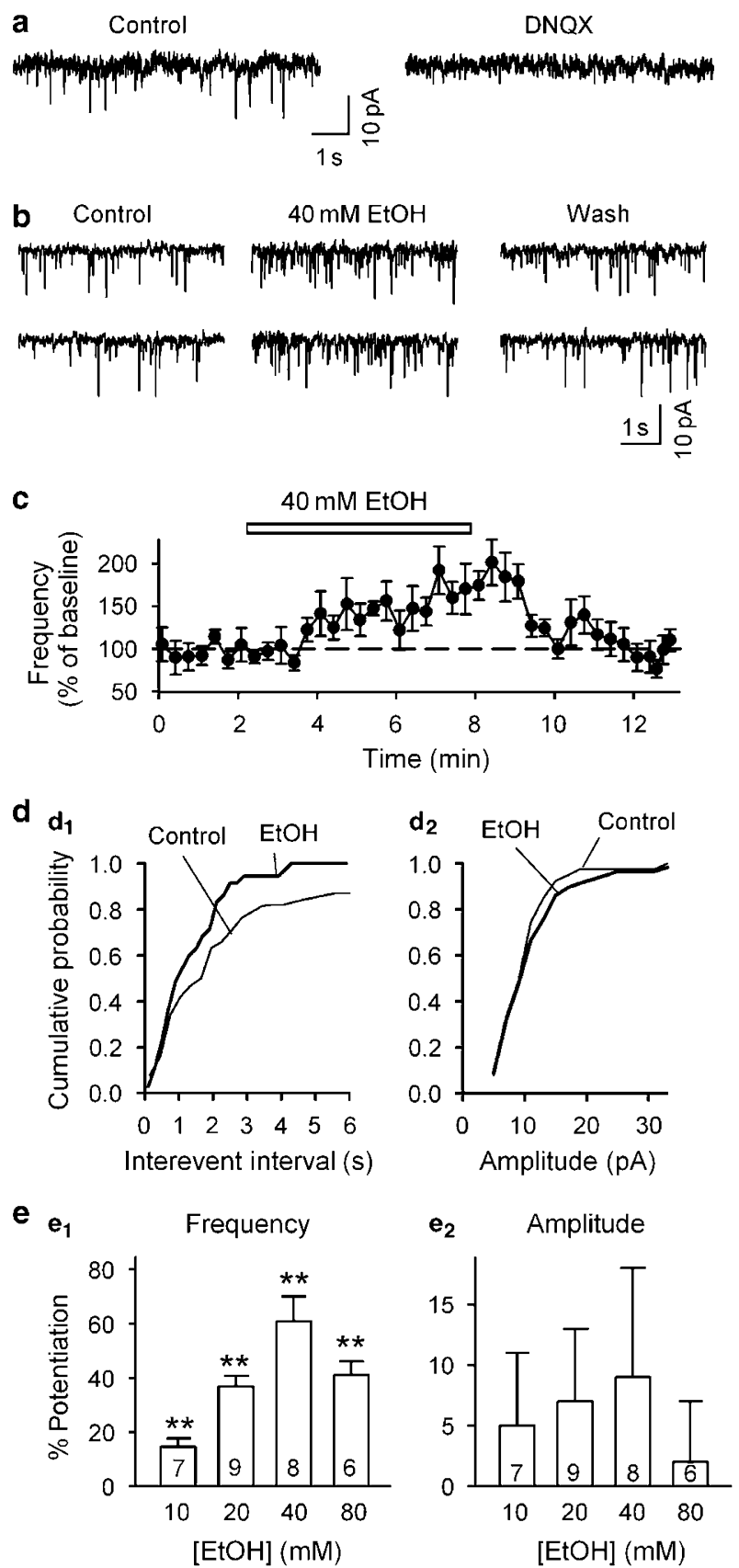

Figure 3 Ethanol increases the frequency of GLUergic spontaneous EPSCs (sEPSCs) recorded in putative DA neurons in midbrain slices. (a) Recorded at $\mathrm{V}_{\mathrm{H}}-70 \mathrm{mV}$ and in bicuculline $(10 \mu \mathrm{M})$, these sEPSCs were suppressed by $20 \mu \mathrm{M}$ DNQX. (b) $40 \mathrm{mM}$ ethanol greatly (but reversibly) increased sEPSC frequency. (c) Time course of mean increase in sEPSC frequency induced by $40 \mathrm{mM}$ ethanol $(n=6)$. (d) Representative cumulative probability plots show increased incidence of short intervals between sEPSCs $\left(d_{1}\right)$, but no change in the amplitude of sEPSCs $\left(d_{2}\right)$. (e) Dose-dependent potentiation of sEPSC frequency $\left(e_{1}\right)$, but unaltered amplitude $\left(e_{2}\right)$ (means $\left.\pm S E M\right)$. (Number of cells in each group is indicated). *** $p<0.0$ I, paired $t$-test for ethanol application vs pre-ethanol control.

amplitude $(17.9 \pm 1.7 \mathrm{pA}$ in control, $17.1 \pm 1.8 \mathrm{pA}$ in TTX, $p=0.26, n=5)$. Ethanol $(40 \mathrm{mM})$ did not significantly alter either the frequency or the amplitude of such mEPSCs (Figure 4a-b): the frequency changed by only $4 \pm 3 \%(n=7$, $p=0.7$, control, $0.7 \pm 0.2$; ethanol, $0.8 \pm 0.2 \mathrm{~Hz}$ ) and the 
amplitudes by $1 \pm 5 \%(n=7, p=1$, control, $6.7 \pm 0.6 \mathrm{pA}$; ethanol, $6.7 \pm 0.4 \mathrm{pA}$ ). These results indicate that ethanol's action is linked to TTX-sensitive $\mathrm{Na}^{+}$channels.

\section{Ethanol-Induced Increase in Glutamatergic Activity is Eliminated by a $D_{1} R$ Antagonist}

Systemic administration of ethanol increases somatodendritic dopamine release from the VTA in vivo (Campbell et al, 1996). In the VTA, $D_{1}$ Rs are expressed on GLUergic axons (Lu et al, 1997) but not on the soma of DA neurons (Mansour et al, 1992; Lu et al, 1997). The activation of $\mathrm{D}_{1} \mathrm{Rs}$ increases glutamate levels in the VTA (Kalivas and Duffy, 1995) as well as glutamatergic transmission in the globus pallidus (Hernandez et al, 2007). To test for a possible involvement of $\mathrm{D}_{1} \mathrm{Rs}$ in ethanol-induced enhancement of GLUergic transmission, we compared the effect of ethanol on sEPSC frequency in the absence and presence of $10 \mu \mathrm{M}$ SKF83566, a $\mathrm{D}_{1} \mathrm{R}$ antagonist. All sEPSCs were recorded in the presence of $10 \mu \mathrm{M}$ bicuculline. As illustrated in Figure $5 \mathrm{a}, 40 \mathrm{mM}$ ethanol produced the usual increase in sEPSC frequency. Though SKF83566 $(10 \mu \mathrm{M})$ itself did not alter baseline sEPSC frequency, it suppressed the effect of ethanol $(40 \mathrm{mM})$. On five cells, ethanol $(40 \mathrm{mM})$ alone increased sEPSC frequency by $53.0 \pm 12.3 \%(p<0.01)$, but it did not significantly change sEPSC frequency in the presence of SKF83566 $(2.3 \pm 15.3 \%, p>0.5)$. These results show that $D_{1} R s$ are essential for the action of ethanol on GLUergic transmission. This would be in line with evidence that dopamine $\mathrm{D}_{1}$ Rs increase intra-terminal $\mathrm{Ca}^{2+}$ levels through $\mathrm{Na}^{+}$channel-mediated membrane depolarization (Wu et al, 2006). Also relevant may be the finding that TTX reduces somatodendritic dopamine release (Chen et al,
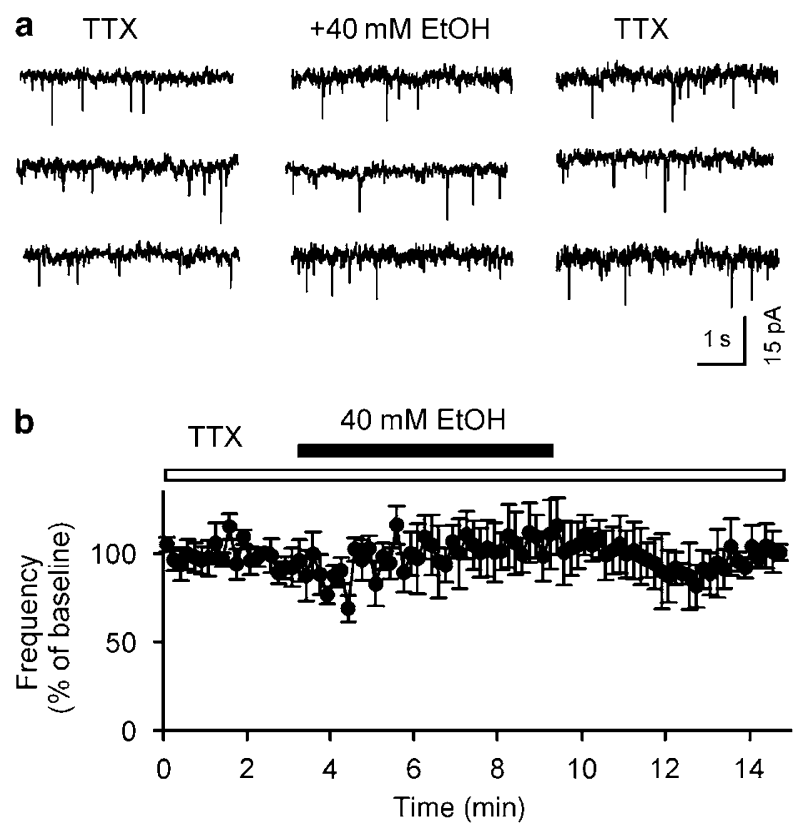

Figure 4 Ethanol has no effect on miniature EPSCs (mEPSCs). The mEPSCs were recorded in VTA DA neurons at $\mathrm{V}_{\mathrm{H}}-70 \mathrm{mV}$, in the presence of bicuculline $(10 \mu \mathrm{M})$ and tetrodotoxin $(T \mathrm{~T}, \mathrm{I} \mu \mathrm{M})$. (a) $40 \mathrm{mM}$ ethanol did not change the incidence of mEPSCs. (b) Plot of mean ( \pm SEM) frequency of mEPSCs for seven cells shows no change in $40 \mathrm{mM}$ ethanol.
1991; Kalivas and Duffy, 1991; Chen and Reith, 1994; Cragg and Greenfield, 1997; Reith et al, 1997).

For another index of ongoing glutamate release, we measured extracellular glutamate levels in the VTA in acute midbrain slices. After collecting samples from slices in standard ACSF, we applied ethanol in the bath. Samples were collected again between 1 and 6 min after the start of ethanol superfusion. Ethanol $(40 \mathrm{mM})$ sharply increased glutamate levels in the samples by $150 \pm 49 \%$ (from $69 \pm 27 \mathrm{nM}$ in control to $144 \pm 35 \mathrm{nM}$ in $40 \mathrm{mM}$ ethanol, $n=6$ slices, $p<0.01$, Figure $5 \mathrm{~b}$, left column). Although the $\mathrm{D}_{1} \mathrm{R}$ antagonist SKF83566 $(5 \mu \mathrm{M})$ alone had no significant effect on glutamate levels, in the presence of SKF83566 $(5 \mu \mathrm{M}), 40 \mathrm{mM}$ ethanol was ineffective (sampled glutamate
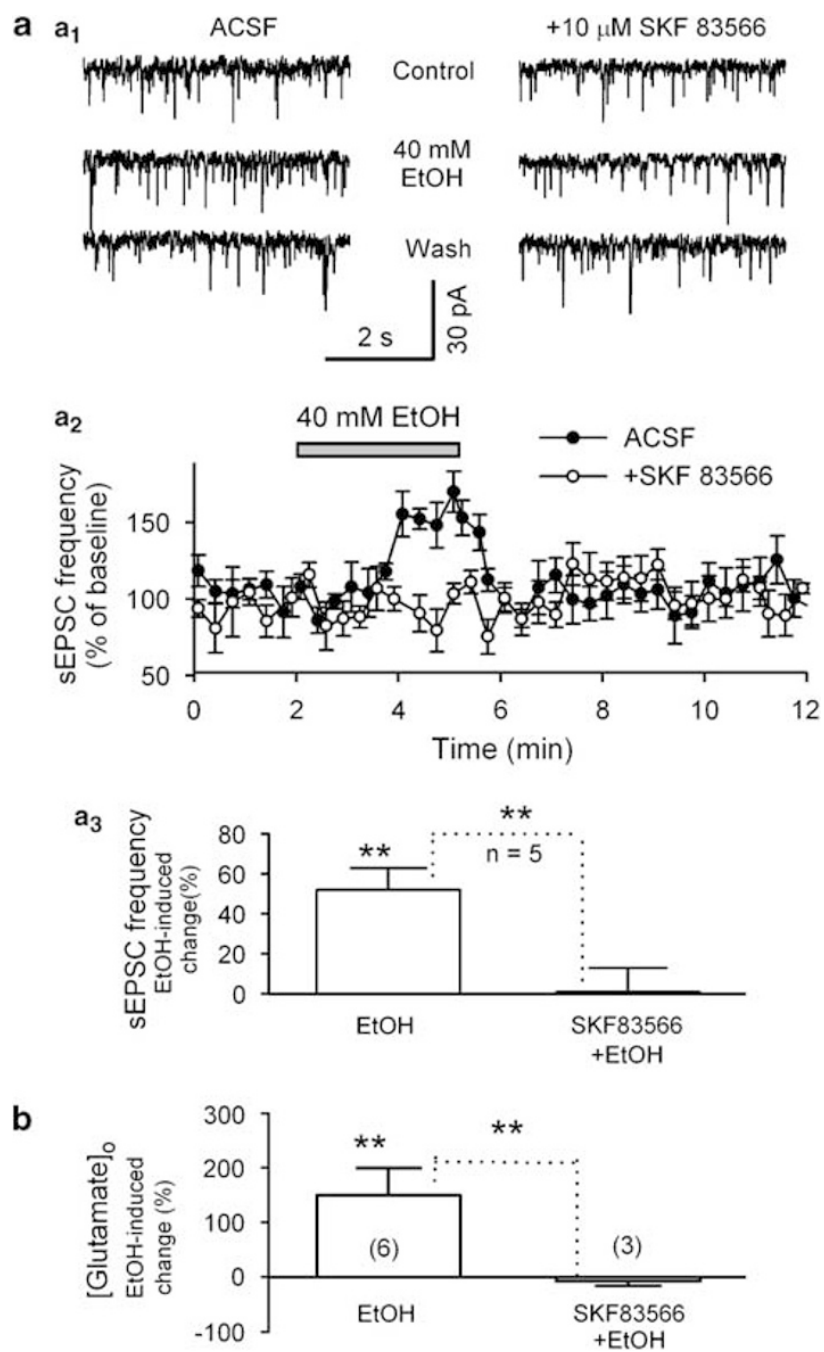

Figure 5 Dopamine $D_{1} R$ antagonist eliminates ethanol-induced facilitation of glutamate release. $\left(a_{1}\right)$ Traces recorded from a putative DA neuron show that ethanol reversibly increased the frequency of sEPSCs in the absence (left panel), but not in the presence (right panel), of $10 \mu \mathrm{M}$ SKF83566 ( $D_{1} R$ antagonist). ( $\left.a_{2}\right)$ Time course of ethanol effect on sEPSC frequency in the absence (ACSF) or presence of $10 \mu \mathrm{M}$ SKF83566. (a) Summary of ethanol-induced changes in sEPSC frequency (mean + SEM from five cells). (b) Ethanol-induced increase in glutamate concentration in fluid samples collected from the VTA in midbrain slices was blocked by SKF83566. Summary of $\%$ changes in (glutamate) caused by $40 \mathrm{mM}$ ethanol alone (data from six slices). ${ }^{* *} p<0.01$, paired $t$-test for drug application vs pre-drug control. 
changed by $-8 \pm 8 \%$ : from $106 \pm 17 \mathrm{nM}$ in SKF 83566 to $99 \pm 20 \mathrm{nM}$ in SKF $83566+40 \mathrm{mM}$ ethanol, $n=3, p>0.5$, Figure 5b, right column).

\section{Effects of Ethanol and $D_{1} R$ Agonist on sEPSC Frequency}

In further tests of the involvement of $D_{1} R s$, we applied SKF38393, a $D_{1} R$ agonist. As illustrated in Figure $6 a_{1-3}$, $100 \mathrm{nM}$ SKF38393 significantly increased sEPSC frequency. This effect was fully reversible, the sEPSC frequency soon returning to its control level after washout (Figure $6 a_{2}$, and more details in the upper panels of Figure $\left.6 b_{1}\right)$. However, there was no significant change in sEPSC amplitudes (data not shown). As illustrated in Figure $6 a_{3}$, the effects of SKF38393 were dose-dependent: 10, 100, 1000, and $3000 \mathrm{nM}$ SKF38393 increased sEPSC frequency by $38 \pm 3 \%(n=9$, $p<0.01), 68 \pm 13 \% \quad(n=7, \quad p<0.001), 121 \pm 28 \% \quad(n=7$, $p=0.001)$, and $102 \pm 20 \%(n=4, p<0.01)$, respectively. There were no corresponding changes in sEPSC amplitude: $5 \pm 4 \%(n=9, p=0.31) ; 10 \pm 9 \%(n=7, p=0.22), 0 \pm 8 \%$ $(n=7, p=0.24)$, and $-3 \pm 10 \%(n=4, p=0.84)$, respectively, (data not shown). These results, which closely parallel the effects of ethanol, provide additional evidence for the presence of functional $D_{1}$ Rs that modulate synaptic glutamate release.

Bearing in mind that (1) ethanol enhanced sEPSCs through the $D_{1} R$-related pathway, and that (2) $D_{1} R$ activation mimicked ethanol effects, we tested the effect of ethanol on $D_{1} R$ using submaximal concentrations of ethanol and $D_{1} R$ agonist, to avoid occlusion resulting from maximal activation of $D_{1}$ Rs by either agent. We compared the changes in sEPSC frequency produced by the $D_{1} R$ agonist SKF $38393(10 \mathrm{nM})$ in the absence and presence of $20 \mathrm{mM}$ ethanol (Figure $6 \mathrm{~b}_{1-2}$ ). When applied alone, $10 \mathrm{nM}$ SKF38393 increased sEPSC frequency by $47 \pm 9 \%(n=5, p<0.01$, in comparison with the pre-drug control, Figure $6 b_{1}$ upper panels, and $6 b_{2}$ ). The sEPSC frequency almost completely recovered after $10 \mathrm{~min}$ washout of SKF38393. Then, we preincubated the slice with $20 \mathrm{mM}$ ethanol for $>10 \mathrm{~min}$, which increased the sEPSC frequency (Figure $6 b_{1}$ ). On the higher but stable baseline frequency recorded in the presence of ethanol, the addition of $10 \mathrm{nM}$ SKF38393 induced a much greater rise in the sEPSC frequency (by $87 \pm 11 \%, n=5, p<0.01$, Figure $6 b_{1-2}$ ) $(n=5, p<0.01)$. This suggests that ethanol enhances $D_{1} R$ function.

\section{Are Dopamine Levels in the VTA Crucial for Ethanol's Action?}

Although susceptible to block by the $D_{1} R$ antagonist, ethanol's action could be independent of the dopamine level. In that case, ethanol should be effective even when the dopamine level is decreased. To test this possibility, we applied ethanol to midbrain slices in which dopamine was depleted by reserpine. Because reserpine was dissolved in acetic acid (final concentration $1 / 5000 \mathrm{v} / \mathrm{v}$ ), control tests were done on slices pretreated for $>90 \mathrm{~min}$ with this concentration of the vehicle alone. Under these conditions, ethanol $(40 \mathrm{mM})$ elicited the usual increase in sEPSC
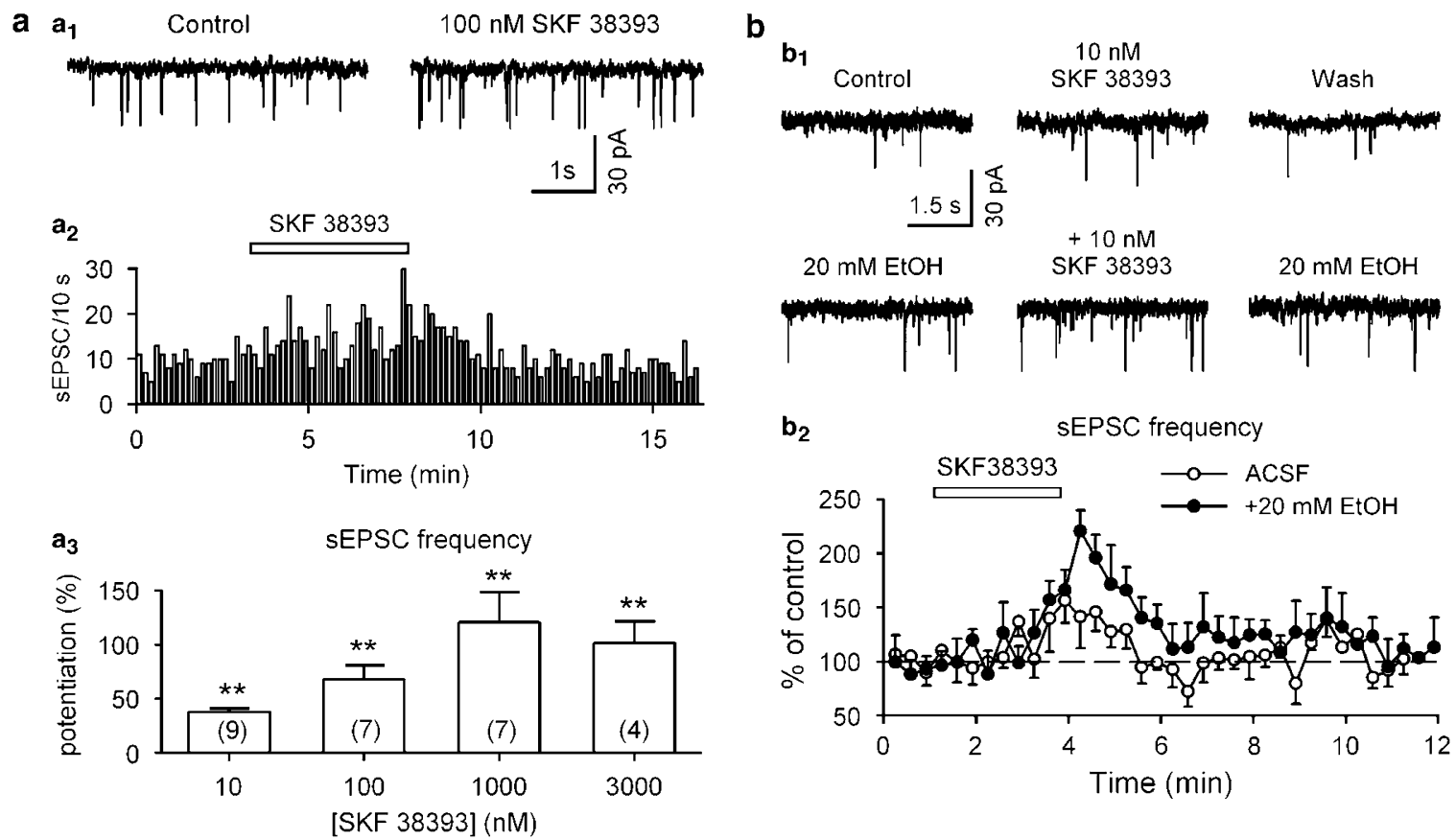

Figure $6 D_{1} R$ agonist mimics the effects of ethanol on sEPSC frequency. $\left(a_{1}-2\right)$ the $D_{1} R$ agonist SKF38393 (I00 nM) increased sEPSC frequency in putative VTA DA neurons. $\left(a_{3}\right)$ Dose-response relation for SKF38393-induced increase in sEPSC frequency. (b/) SKF38393 (I 0 nM) reversibly enhanced sEPSC frequency (upper traces). EtOH (20 mM) also increased sEPSC frequency (lower left trace). In the presence of $20 \mathrm{mM}$ EtOH, SKF38393 (I $0 \mathrm{nM}$ ) further increased sEPSC frequency (lower middle trace). ( $\left.b_{2}\right)$ Average time course of changes in sEPSC frequency induced by $10 \mathrm{nM}$ SKF38393 in the absence (ACSF) and presence of $20 \mathrm{mM}$ ethanol ( $+20 \mathrm{mM} \mathrm{EtOH}$; means \pm SEM; data from five cells). Open bar indicates the duration of SKF38393 application; baseline (100\%) represents pre-SKF38393 frequency in the presence of ACSF or $20 \mathrm{mM}$ EtOH. *** $<0.01$, paired $t$-test for SKF38393 application vs pre-SKF38393. 
frequency (by $109 \pm 46 \%$; from $1.7 \pm 0.6$ to $2.8 \pm 0.7 \mathrm{~Hz}$, $p<0.01, n=5$, Figure $7 a_{1}$ and the left column in Figure $7 a_{3}$ ). By contrast, $40 \mathrm{mM}$ ethanol was ineffective when applied to slices pretreated for similar periods with $10 \mu \mathrm{M}$ reserpine (Figure $7 \mathrm{a}_{2}$ ), sEPSC frequency changing by $-14 \pm 10 \%$ of control (from $1.2 \pm 0.3$ to $1.0 \pm 0.3 \mathrm{~Hz}, n=5$; Figure $7 \mathrm{a}_{3}$ ). This result indicates that the release of dopamine is necessary for ethanol's action.

An important mechanism is suggested by previous evidence that acute administration of ethanol (i.p.) elevates extracellular dopamine levels in the VTA in vivo (Campbell et al, 1996; Yan et al, 2005). To elicit a similar rise in local dopamine levels in slices, we applied GBR 12935, a selective blocker of dopamine transport. As illustrated in Figure $7 \mathrm{~b}$, $20 \mathrm{nM}$ GBR12935 significantly and reversibly increased the frequency of sEPSCs recorded in VTA DA neurons (by
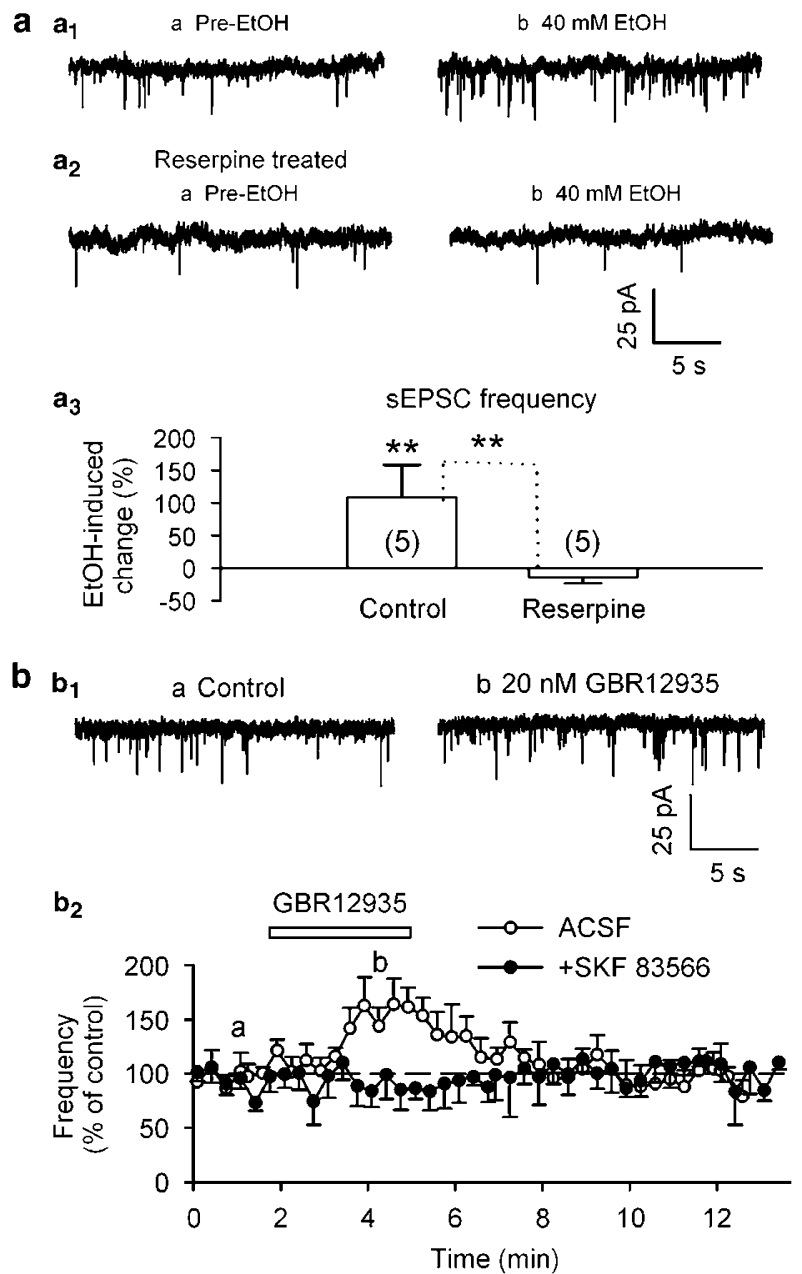

Figure 7 Effects of ethanol on sEPSC frequency are suppressed by dopamine depletion and mimicked by block of dopamine transport. $\left(\mathrm{a}_{\mathbf{l}}-2\right)$ Although $40 \mathrm{mM}$ ethanol induced typical increase in sEPSC frequency in slice pretreated for $>90 \mathrm{~min}$ with acetic acid $(\mathrm{v} / \mathrm{v}=1 / 5000$, the vehicle for reserpine) $\left(a_{1}\right)$, there was no such effect in slice pretreated with $10 \mu \mathrm{M}$ reserpine for $>90 \mathrm{~min}\left(\mathrm{a}_{2}\right)$. ( $\left.\mathrm{a}_{3}\right)$ Summary of effects of reserpine (data from five cells). *** $p<0.01$, paired $t$-test for ethanol application vs preethanol control or, as indicated, nonpaired t-test for control (acetic acid) group vs reserpine group. $\left(b_{1}\right)$ Increase in sEPSC frequency produced by GBRI2935 (20 nM, a dopamine transport blocker). ( $\left.b_{2}\right)$ The effect of GBRI 2935 is blocked by the $D_{1} R$ antagonist SKF83566 $(10 \mu M, n=6)$.
$48 \pm 11 \%, n=6, p=0.01)$. Similar to ethanol, GBR12935 was ineffective in the presence of the $D_{1} R$ antagonist SKF83566 $(10 \mu \mathrm{M})$ (the sEPSC frequency changed by $2 \pm 4 \%, n=6$, $p=0.16$, Figure $7 b_{2}$ ). This finding shows that a rise in the endogenous dopamine level also mimics the action of ethanol.

As ethanol-induced enhancement of sEPSCs depends on dopamine release, the smaller effect of ethanol at $80 \mathrm{mM}$ than at $40 \mathrm{mM}$ could result from the activation of $\mathrm{D}_{2}$-like dopamine receptors $\left(D_{2} R\right)$; it is known that dopamine and other agonists at high concentrations can activate $D_{2} R s$, which inhibit glutamate release (Koga and Momiyama, 2000). To test this possibility, we compared the effects of ethanol $(20$ and $80 \mathrm{mM})$ in the absence and presence of $10 \mu \mathrm{M}$ raclopride, a $\mathrm{D}_{2} \mathrm{R}$ antagonist: $80 \mathrm{mM}$ ethanol alone increased sEPSC frequency by $38 \pm 10 \%(n=5, p=0.02)$; in the presence of raclopride, $80 \mathrm{mM}$ ethanol induced a much greater increase in frequency, by $173 \pm 33 \%(n=5, p<0.01)$. This difference is significant $(n=5, p<0.05$, paired $t$-test, ethanol $v s$ ethanol + raclopride). Nevertheless, $20 \mathrm{mM}$ ethanol similarly increased sEPSC frequency in the absence (37 $\pm 7 \%, n=4, p=0.006)$ and the presence of raclopride $(43 \pm 10 \%, n=4, p=0.01)(p=0.4$, paired $t$-test). These results support the idea that the reduced efficacy of ethanol at high concentrations - and the consequent bell-shaped ethanol dose-response relation-are probably caused by the activation of $\mathrm{D}_{2} \mathrm{Rs}$.

\section{Effects of an AMPA Receptor Antagonist on Ethanol-Induced Excitation of VTA Dopamine Neurons}

To assess the contribution of glutamatergic transmission to the overall facilitating action of ethanol, we examined the effect of $10 \mu \mathrm{M}$ DNQX (an AMPA/KA-type glutamate antagonist) on the ethanol-induced increase in spontaneous firing of putative DA neurons. On average, $40 \mathrm{mM}$ ethanol alone increased the firing rate by $19.2 \pm 6.0 \% \quad(n=10$, $p<0.01)$. In the presence of DNQX, $40 \mathrm{mM}$ ethanol increased the firing rate by $12.4 \pm 3.2 \%(n=10, p<0.01)$, indicating a $\sim 35 \%$ reduction of ethanol's effect $(n=10$, $p<0.01)$. Thus, ethanol facilitation of GLUergic transmission contributes significantly to the excitation of VTA DA neurons.

\section{DISCUSSION}

Our major finding is that clinically relevant concentrations of ethanol increase glutamate release onto VTA DA neurons. Moreover, this intriguing action of ethanol is mediated by presynaptic $D_{1}$ Rs. These effects were produced by concentrations of ethanol close to the blood alcohol levels observed in rats after voluntary ethanol consumption (Robinson et al, 2000; Doyon et al, 2003, 2005). Even more relevant is the virtually identical bell-shaped concentrationdependence of the effects of ethanol in our experiments and in those of Rodd et al (Rodd et al, 2004), who measured ethanol self-injected by rats directly into VTA. As glutamate has a major role in mediating the behavioral manifestations of ethanol consumption (Eckardt et al, 1998), increased glutamate release in VTA could be an important aspect of alcohol addiction. 
Ethanol Enhances Glutamatergic Transmission to VTA DA Neurons by Activation of Presynaptic $D_{1} R s$

Several lines of evidence indicate that ethanol increases synaptic glutamate release in VTA. Ethanol enhanced the amplitude but decreased the paired-pulse ratio of evoked EPSCs. It increased sEPSC frequency without affecting their amplitude. Furthermore, it raised the extracellular glutamate level in VTA. The absence of any change in mEPSC frequency is clear evidence of the involvement of TTX-sensitive $\mathrm{Na}^{+}$channels. Ethanol did not alter the amplitude of both sEPSCs and mEPSCs, indicating that ethanol has no effect on postsynaptic AMPA receptors. This is probably because (1) ethanol's effects on AMPARs are small at relatively low concentrations $(<80 \mathrm{mM})$; (2) synaptic AMPARs in juvenile neurons are more resistant to ethanol (Mameli et al, 2005); (3) ethanol could activate some unknown internal signaling pathway in VTA DA neurons, which counteracts direct inhibition of AMPARs.

Dopamine receptors consist of $D_{1}$-like $\left(D_{1}\right.$ and $D_{5}$ receptors) and $D_{2}$-like $\left(D_{2}, D_{3}\right.$ and $D_{4}$ receptors) families. Dopamine receptors of both the $\mathrm{D}_{2}$ family (in particular $\mathrm{D}_{2} \mathrm{R}$ ) (Blum et al, 1990) and $\mathrm{D}_{1} \mathrm{R}$ have been implicated in the mechanisms of drug dependence and abuse: for example, disruption of $\mathrm{D}_{1} \mathrm{R}$ gene expression (El-Ghundi et al, 1998) or administration of $\mathrm{D}_{1} \mathrm{R}$ antagonist (Liu and Weiss, 2002) attenuates or prevents alcohol-seeking behavior.

In our experiments, a $D_{1} R$ antagonist eliminated ethanol facilitation of sEPSC frequency. That ethanol enhances glutamate release by $D_{1} R$ activation was confirmed by our in vitro assays: ethanol raised extracellular glutamate levels, and this effect was eliminated by a $D_{1} R$ antagonist. Moreover, like ethanol, a $D_{1} R$ agonist increased sEPSC frequency without affecting their amplitude. These results suggest that ethanol enhances glutamate release by activating $\mathrm{D}_{1}$ Rs. In the midbrain, a $\mathrm{D}_{1} \mathrm{R}$ agonist modulates action potential-dependent glutamate release (Kalivas and Duffy, 1995), and, in the globus pallidus, it increases the frequency but not the amplitude of sEPSCs (Hernandez et al, 2007). Our observation that ethanol did not change mEPSCs suggests that ethanol may not directly activate $D_{1}$ Rs.

\section{How Does Ethanol Activate Presynaptic $D_{1} R s$ ?}

In reserpine-treated slices, in which dopamine is depleted, ethanol failed to alter sEPSC frequency. This further excludes ethanol's direct activation of presynaptic $D_{1}$ Rs. Our finding that ethanol enhanced the action of a $D_{1} R$ agonist on sEPSCs supports the possibility that ethanol potentiates dopamine's action on presynaptic $\mathrm{D}_{1} \mathrm{Rs}$. But the similar effects of ethanol and dopamine reuptake blocker rather point to a rise in extracellular dopamine concentration, which could result from ethanol-induced somatodendritic dopamine release and/or block of dopamine reuptake, in keeping with previous evidence that systemically administered ethanol $(1-2 \mathrm{~g} / \mathrm{kg})$ raises extracellular dopamine in VTA (Campbell et al, 1996; Yan et al, 2005). Therefore, in addition to the potentiation of $D_{1} R$ function, the enhancement of dopamine release would activate a positive feedback pathway through which ethanol facilitates both glutamate and dopamine release. This hypothesis is supported by previous studies showing that ethanol stimulates DA neurons (Brodie et al, 1990, 1999a, b; Xiao et al, 2007); and also somatodendritic dopamine release (Campbell et al, 1996; Yan et al, 2005) in VTA. The lack of effect of ethanol on mEPSCs provides additional support, as dopamine release in VTA is TTX sensitive (Kalivas and Duffy, 1991; Chen and Reith, 1994; Cragg and Greenfield, 1997). Note that ethanol significantly excites VTA DA neurons only at relatively high concentrations $(\geqslant 80 \mathrm{mM})$. Thus, ethanol may enhance glutamate release by potentiation of $D_{1} R$ function at low concentrations $(\leqslant 40 \mathrm{mM})$, and potentiate both $\mathrm{D}_{1} \mathrm{R}$ function and dopamine release at higher concentrations.

A rise in local dopamine levels is also suggested by the bell-shaped dose-dependence of ethanol's action, both in our experiments and in the in vivo experiments of Rodd et al (2004). This may result from opposite effects of dopamine (the nonselective endogenous agonist) acting on different receptors. At low concentration, dopamine appears to bind predominantly to $\mathrm{D}_{1} \mathrm{Rs}$ and at higher concentrations to $\mathrm{D}_{2}$ Rs. Thus, Trantham-Davidson et al (2004) found that low concentrations of dopamine $(<0.5 \mu \mathrm{M})$ enhanced IPSCs by activating mainly $\mathrm{D}_{1}$ Rs, whereas higher concentrations of dopamine $(>1 \mu \mathrm{M})$ reduced IPSCs by predominantly activating $\mathrm{D}_{2} \mathrm{Rs}$. In comparable experiments on VTA and globus pallidus, Koga and Momiyama (2000) and Hernandez et al (2007) found that dopamine or a $\mathrm{D}_{2}$ agonist inhibits EPSCs in DA neurons through presynaptic $\mathrm{D}_{2}$ Rs (in VTA, with a high $\mathrm{IC}_{50}$ of $16 \mu \mathrm{M}$ for dopamine). That the bell-shaped concentration dependence of ethanol's action in VTA slices is due to opposite presynaptic actions through $D_{1} R s$ and then $\mathrm{D}_{2} \mathrm{Rs}$ is strongly supported by our finding that the facilitation of sEPSCs by $80 \mathrm{mM}$ ethanol was greatly potentiated when $\mathrm{D}_{2}$ Rs were blocked.

In the present study, we found that acute ethanol enhances glutamate release at synapses on VTA DA neurons. This is quite likely a result of the unique anatomical organization of VTA and its responses to ethanol. In VTA, dopamine released somatodendritically appears to modulate glutamate release by activating both $\mathrm{D}_{1} \mathrm{Rs}$ and $\mathrm{D}_{2} \mathrm{Rs}$ on adjacent GLUergic terminals. Ethanol could stimulate glutamate release through either potentiation of the presynaptic $D_{1} R s$ or potentiation of these $D_{1} R s$ and dopamine release. In previous studies, ethanol inhibited glutamate release in the hippocampus by inhibiting N-, P/Q-type voltagedependent calcium channels (VDCCs) (Maldve et al, 2004; Mameli et al, 2005), in NAcc by stimulating opioid peptide release (Nie et al, 1993, 1994), or by activating $\mathrm{GABA}_{\mathrm{B}}$ receptors (Steffensen et al, 2000). Anatomically, these pathways may be relevant for the effect of ethanol on glutamate release in VTA. However, $D_{1}$ Rs drive the activation of protein kinase $A$, which is known to antagonize ethanol inhibition of $\mathrm{N}$ - and P/Q-type VDCCs (Solem et al, 1997). Although $\mu$-opioid receptors are sparsely expressed on GLUergic terminals (Garzon and Pickel, 2001), their activation also disinhibits VTA DA neurons (Johnson et al, 1992; Xiao et al, 2007), resulting in increased dopamine release. Hence, the inhibition of glutamate release may be counteracted by $\mathrm{D}_{1} \mathrm{R}$ activation. In the NAcc and hippocampus, 
ethanol increases GABA release, which activates $G_{A B A}$ receptors (Siggins et al, 2005); whereas we and others demonstrated that ethanol reduces GABA release in VTA (Gallegos et al, 1999; Stobbs et al, 2004; Xiao et al, 2007, Xiao and Ye, 2008). Therefore, in VTA, ethanol may not inhibit glutamate release by activating $\mathrm{GABA}_{B}$ receptors. Although there may be other pathways involved in ethanol's effect on glutamate release in some other brain areas, our data suggest that ethanol affects these pathways in a different manner in VTA and that dopamine receptor activation alleviates their impact.

\section{Enhancement of Glutamate Release as an Indirect Mechanism of Ethanol Excitation of VTA DA Neurons}

Previous studies have shown that ethanol can directly excite DA neurons in VTA in vivo (Gessa et al, 1985) and in slices (Brodie et al, 1990; Okamoto et al, 2006; Xiao et al, 2007), as well as enzymatically dissociated DA neurons (Brodie et al, 1999a). Such direct effects were minimal with ethanol concentrations of $40 \mathrm{mM}$ (at which ethanol produced its maximum effect in the current experiments) and were prominent only with ethanol at $\geqslant 80 \mathrm{mM}$. Major direct actions on DA neurons were therefore unlikely in our experiments.

VTA DA neurons receive numerous inputs that can modulate their eventual output. Integration of the synaptic inputs and the intrinsic properties sets the frequency and pattern of firing (Mereu et al, 1997; Kitai et al, 1999; Johnson and $\mathrm{Wu}, 2004)$. Our finding that blockade of GLUergic transmission substantially attenuated but did not abolish ethanol's ( $40 \mathrm{mM}$ ) effect on DA cell firing, indicates that potentiation of GLUergic transmission is not the sole mechanism of ethanol action in VTA. Other mechanisms include disinhibition (Xiao et al, 2007), as well as direct excitation of VTA DA neurons - though the latter may become a major factor only when (ethanol) rises $>40 \mathrm{mM}$ (Brodie et al, 1990).

In conclusion, the present study shows that ethanolinduced facilitation of glutamatergic transmission increases firing of VTA DA neurons. This effect is mediated by somatodendritically released dopamine, which activates $\mathrm{D}_{1} \mathrm{Rs}$ on GLUergic terminals, causing an increase in glutamate release. The resulting acceleration in DA neuronal firing leads to further increase in dopamine release. By potentiating dopamine's action on presynaptic $\mathrm{D}_{1} \mathrm{Rs}$ and thus augmenting dopamine release, ethanol reinforces a positive feedback loop, that may constitute the neuronal substrate of ethanol addiction.

\section{ACKNOWLEDGEMENTS}

This work was made possible by NIH Grant AA15925, AA016964 (JHY), UMDNJ foundation (JHY), AA013852 (MFO). We thank Dr David Lovinger for his helpful comments on this work.

\section{DISCLOSURE}

The authors declare no conflict of interest.

\section{REFERENCES}

Blum K, Noble EP, Sheridan PJ, Montgomery A, Ritchie T, Jagadeeswaran P et al (1990). Allelic association of human dopamine D2 receptor gene in alcoholism. JAMA 263: 2055-2060.

Bonci A, Malenka RC (1999). Properties and plasticity of excitatory synapses on dopaminergic and GABAergic cells in the ventral tegmental area. J Neurosci 19: 3723-3730.

Bonci A, Williams JT (1997). Increased probability of GABA release during withdrawal from morphine. J Neurosci 17: 796-803.

Brodie MS, McElvain MA, Bunney EB, Appel SB (1999b). Pharmacological reduction of small conductance calciumactivated potassium current (SK) potentiates the excitatory effect of ethanol on ventral tegmental area dopamine neurons. J Pharmacol Exp Ther 290: 325-333.

Brodie MS, Pesold C, Appel SB (1999a). Ethanol directly excites dopaminergic ventral tegmental area reward neurons. Alcohol Clin Exp Res 23: 1848-1852.

Brodie MS, Shefner SA, Dunwiddie TV (1990). Ethanol increases the firing rate of dopamine neurons of the rat ventral tegmental area in vitro. Brain Res 508: 65-69.

Campbell AD, Kohl RR, McBride WJ (1996). Serotonin-3 receptor and ethanol-stimulated somatodendritic dopamine release. Alcohol 13: 569-574.

Chen JF, Qin ZH, Szele F, Bai G, Weiss B (1991). Neuronal localization and modulation of the D2 dopamine receptor mRNA in brain of normal mice and mice lesioned with 6-hydroxydopamine. Neuropharmacology 30: 927-941.

Chen NH, Reith ME (1994). Autoregulation and monoamine interactions in the ventral tegmental area in the absence and presence of cocaine: a microdialysis study in freely moving rats. J Pharmacol Exp Ther 271: 1597-1610.

Cragg SJ, Greenfield SA (1997). Differential autoreceptor control of somatodendritic and axon terminal dopamine release in substantia nigra, ventral tegmental area, and striatum. J Neurosci 17: $5738-5746$.

Dahchour A, Hoffman A, Deitrich R, de Witte P (2000). Effects of ethanol on extracellular amino acid levels in high-and lowalcohol sensitive rats: a microdialysis study. Alcohol Alcohol 35: 548-553.

Doyon WM, Anders SK, Ramachandra VS, Czachowski CL, Gonzales RA (2005). Effect of operant self-administration of $10 \%$ ethanol plus $10 \%$ sucrose on dopamine and ethanol concentrations in the nucleus accumbens. J Neurochem 93: 1469-1481.

Doyon WM, York JL, Diaz LM, Samson HH, Czachowski CL, Gonzales RA (2003). Dopamine activity in the nucleus accumbens during consummatory phases of oral ethanol self-administration. Alcohol Clin Exp Res 27: 1573-1582.

Eckardt MJ, File SE, Gessa GL, Grant KA, Guerri C, Hoffman PL et al (1998). Effects of moderate alcohol consumption on the central nervous system. Alcohol Clin Exp Res 22: 998-1040.

El-Ghundi M, George SR, Drago J, Fletcher PJ, Fan T, Nguyen T et al (1998). Disruption of dopamine D1 receptor gene expression attenuates alcohol-seeking behavior. Eur J Pharmacol 353: $149-158$.

Erhardt S, Schwieler L, Engberg G (2002). Excitatory and inhibitory responses of dopamine neurons in the ventral tegmental area to nicotine. Synapse 43: 227-237.

Gallegos RA, Lee RS, Criado JR, Henriksen SJ, Steffensen SC (1999). Adaptive responses of gamma-aminobutyric acid neurons in the ventral tegmental area to chronic ethanol. J Pharmacol Exp Ther 291: 1045-1053.

Garzon M, Pickel VM (2001). Plasmalemmal mu-opioid receptor distribution mainly in nondopaminergic neurons in the rat ventral tegmental area. Synapse 41: 311-328. 
Gessa GL, Muntoni F, Collu M, Vargiu L, Mereu G (1985). Low doses of ethanol activate dopaminergic neurons in the ventral tegmental area. Brain Res 348: 201-203.

Hernandez A, Sierra A, Valdiosera R, Floran B, Erlij D, Aceves J (2007). Presynaptic D1 dopamine receptors facilitate glutamatergic neurotransmission in the rat globus pallidus. Neurosci Lett 425: $188-191$.

Hodge CW, Samson HH, Chappelle AM (1997). Alcohol selfadministration: further examination of the role of dopamine receptors in the nucleus accumbens. Alcohol Clin Exp Res 21: 1083-1091.

Ikemoto S, McBride WJ, Murphy JM, Lumeng L, Li TK (1997). 6OHDA-lesions of the nucleus accumbens disrupt the acquisition but not the maintenance of ethanol consumption in the alcohol-preferring $\mathrm{P}$ line of rats. Alcohol Clin Exp Res 21: 1042-1046.

Imperato A, Di Chiara G (1986). Preferential stimulation of dopamine release in the nucleus accumbens of freely moving rats by ethanol. J Pharmacol Exp Ther 239: 219-228.

Johnson SW, Mercuri NB, North RA (1992). 5-hydroxytryptamine1B receptors block the GABAB synaptic potential in rat dopamine neurons. J Neurosci 12: 2000-2006.

Johnson SW, North RA (1992). Two types of neurone in the rat ventral tegmental area and their synaptic inputs. $J$ Physiol 450: 455-468.

Johnson SW, Wu YN (2004). Multiple mechanisms underlie burst firing in rat midbrain dopamine neurons in vitro. Brain Res 1019: 293-296.

Jones S, Kauer JA (1999). Amphetamine depresses excitatory synaptic transmission via serotonin receptors in the ventral tegmental area. J Neurosci 19: 9780-9787.

Kalivas PW, Duffy P (1991). A comparison of axonal and somatodendritic dopamine release using in vivo dialysis. J Neurochem 56: 961-967.

Kalivas PW, Duffy P (1995). D1 receptors modulate glutamate transmission in the ventral tegmental area. J Neurosci 15: 5379-5388.

Kitai ST, Shepard PD, Callaway JC, Scroggs R (1999). Afferent modulation of dopamine neuron firing patterns. Curr Opin Neurobiol 9: 690-697.

Koga E, Momiyama T (2000). Presynaptic dopamine D2-like receptors inhibit excitatory transmission onto rat ventral tegmental dopaminergic neurones. J Physiol 523(Part 1): 163-173.

Koob GF, Sanna PP, Bloom FE (1998). Neuroscience of addiction. Neuron 21: 467-476.

Krystal JH, Petrakis IL, Mason G, Trevisan L, D’Souza DC (2003). $N$-methyl-D-aspartate glutamate receptors and alcoholism: reward, dependence, treatment, and vulnerability. Pharmacol Ther 99: 79-94.

Lacey MG, Mercuri NB, North RA (1989). Two cell types in rat substantia nigra zona compacta distinguished by membrane properties and the actions of dopamine and opioids. J Neurosci 9: $1233-1241$.

Liu X, Weiss F (2002). Additive effect of stress and drug cues on reinstatement of ethanol seeking: exacerbation by history of dependence and role of concurrent activation of corticotropinreleasing factor and opioid mechanisms. J Neurosci 22: 7856-7861.

Lu XY, Churchill L, Kalivas PW (1997). Expression of D1 receptor mRNA in projections from the forebrain to the ventral tegmental area. Synapse 25: 205-214.

Maldve RE, Chen X, Zhang TA, Morrisett RA (2004). Ethanol selectively inhibits enhanced vesicular release at excitatory synapses: real-time visualization in intact hippocampal slices. Alcohol Clin Exp Res 28: 143-152.

Mameli M, Zamudio PA, Carta M, Valenzuela CF (2005). Developmentally regulated actions of alcohol on hippocampal glutamatergic transmission. J Neurosci 25: 8027-8036.
Mansour A, Meador-Woodruff JH, Zhou Q, Civelli O, Akil H, Watson SJ (1992). A comparison of D1 receptor binding and mRNA in rat brain using receptor autoradiographic and in situ hybridization techniques. Neuroscience 46: 959-971.

Margolis EB, Hjelmstad GO, Bonci A, Fields HL (2003). Kappaopioid agonists directly inhibit midbrain dopaminergic neurons. J Neurosci 23: 9981-9986.

Margolis EB, Hjelmstad GO, Bonci A, Fields HL (2005). Both kappa and mu opioid agonists inhibit glutamatergic input to ventral tegmental area neurons. J Neurophysiol 93: 3086-3093.

Margolis EB, Lock H, Hjelmstad GO, Fields HL (2006). The ventral tegmental area revisited: is there an electrophysiological marker for dopaminergic neurons? J Physiol 577: 907-924.

Melis M, Pistis M, Perra S, Muntoni AL, Pillolla G, Gessa GL (2004). Endocannabinoids mediate presynaptic inhibition of glutamatergic transmission in rat ventral tegmental area dopamine neurons through activation of CB1 receptors. J Neurosci 24: 53-62.

Mereu G, Lilliu V, Casula A, Vargiu PF, Diana M, Musa A et al (1997). Spontaneous bursting activity of dopaminergic neurons in midbrain slices from immature rats: role of $\mathrm{N}$-methyl-Daspartate receptors. Neuroscience 77: 1029-1036.

Ng GY, George SR (1994). Dopamine receptor agonist reduces ethanol self-administration in the ethanol-preferring C57BL/6J inbred mouse. Eur J Pharmacol 269: 365-374.

Nie Z, Madamba SG, Siggins GR (1994). Ethanol inhibits glutamatergic neurotransmission in nucleus accumbens neurons by multiple mechanisms. J Pharmacol Exp Ther 271: $1566-1573$

Nie Z, Yuan X, Madamba SG, Siggins GR (1993). Ethanol decreases glutamatergic synaptic transmission in rat nucleus accumbens in vitro: naloxone reversal. J Pharmacol Exp Ther 266: 1705-1712.

Nowak KL, McBride WJ, Lumeng L, Li TK, Murphy JM (1998). Blocking $\mathrm{GABA}(\mathrm{A})$ receptors in the anterior ventral tegmental area attenuates ethanol intake of the alcohol-preferring $\mathrm{P}$ rat. Psychopharmacology (Berl) 139: 108-116.

Okamoto T, Harnett MT, Morikawa H (2006). Hyperpolarizationactivated cation current (Ih) is an ethanol target in midbrain dopamine neurons of mice. J Neurophysiol 95: 619-626.

Olive MF, Mehmert KK, Hodge CW (2000). Microdialysis in the mouse nucleus accumbens: a method for detection of monoamine and amino acid neurotransmitters with simultaneous assessment of locomotor activity. Brain Res Protoc 5: 16-24.

Price KL, Middaugh LD (2004). The dopamine D1 antagonist reduces ethanol reward for C57BL/6 mice. Alcohol Clin Exp Res 28: $1666-1675$.

Rassnick S, Stinus L, Koob GF (1993). The effects of 6-hydroxydopamine lesions of the nucleus accumbens and the mesolimbic dopamine system on oral self-administration of ethanol in the rat. Brain Res 623: 16-24.

Reith ME, Xu C, Chen NH (1997). Pharmacology and regulation of the neuronal dopamine transporter. Eur J Pharmacol 324: 1-10.

Roberto M, Schweitzer P, Madamba SG, Stouffer DG, Parsons LH, Siggins GR (2004). Acute and chronic ethanol alter glutamatergic transmission in rat central amygdala: an in vitro and in vivo analysis. J Neurosci 24: 1594-1603.

Robinson DL, Lara JA, Brunner LJ, Gonzales RA (2000). Quantification of ethanol concentrations in the extracellular fluid of the rat brain: in vivo calibration of microdialysis probes. J Neurochem 75: 1685-1693.

Rodd ZA, Melendez RI, Bell RL, Kuc KA, Zhang Y, Murphy JM et al (2004). Intracranial self-administration of ethanol within the ventral tegmental area of male Wistar rats: evidence for involvement of dopamine neurons. J Neurosci 24: 1050-1057.

Samson HH, Hodge CW, Tolliver GA, Haraguchi M (1993). Effect of dopamine agonists and antagonists on ethanol-reinforced behavior: the involvement of the nucleus accumbens. Brain Res Bull 30: 133-141. 
Selim M, Bradberry CW (1996). Effect of ethanol on extracellular 5-HT and glutamate in the nucleus accumbens and prefrontal cortex: comparison between the Lewis and Fischer 344 rat strains. Brain Res 716: 157-164.

Shao XM, Feldman JL (2007). Efficient measurement of endogenous neurotransmitters in small localized regions of central nervous systems in vitro with HPLC. J Neurosci Methods 160: 256-263.

Siggins GR, Roberto M, Nie Z (2005). The tipsy terminal: presynaptic effects of ethanol. Pharmacol Ther 107: 80-98.

Solem M, McMahon T, Messing RO (1997). Protein kinase A regulates regulates inhibition of $\mathrm{N}$ - and $\mathrm{P} / \mathrm{Q}$-type calcium channels by ethanol in PC12 cells. J Pharmacol Exp Ther 282: 1487-1495.

Steffensen SC, Nie Z, Criado JR, Siggins GR (2000). Ethanol inhibition of $N$-methyl-D-aspartate responses involves presynaptic gamma-aminobutyric acid(B) receptors. J Pharmacol Exp Ther 294: 637-647.

Stobbs SH, Ohran AJ, Lassen MB, Allison DW, Brown JE, Steffensen SC (2004). Ethanol suppression of ventral tegmental area GABA neuron electrical transmission involves $N$-methyl-Daspartate receptors. J Pharmacol Exp Ther 311: 282-289.

Suaud-Chagny MF, Chergui K, Chouvet G, Gonon F (1992). Relationship between dopamine release in the rat nucleus accumbens and the discharge activity of dopaminergic neurons during local in vivo application of amino acids in the ventral tegmental area. Neuroscience 49: 63-72.

Trantham-Davidson H, Neely LC, Lavin A, Seamans JK (2004). Mechanisms underlying differential D1 versus D2 dopamine receptor regulation of inhibition in prefrontal cortex. $J$ Neurosci 24: 10652-10659.

Wang B, Shaham Y, Zitzman D, Azari S, Wise RA, You ZB (2005). Cocaine experience establishes control of midbrain glutamate and dopamine by corticotropin-releasing factor: a role in stressinduced relapse to drug seeking. J Neurosci 25: 5389-5396.

Wu J, Dougherty JJ, Nichols RA (2006). Dopamine receptor regulation of $\mathrm{Ca}^{2+}$ levels in individual isolated nerve terminals from rat striatum: comparison of presynaptic D1-like and D2like receptors. J Neurochem 98: 481-494.

Xiao C, Zhang J, Krnjevic K, Ye JH (2007). Effects of ethanol on midbrain neurons: role of opioid receptors. Alcohol Clin Exp Res 31: 1106-1113.

Xiao C, Ye JH (2008). Ethanol dually modulates GABAergic synaptic transmission onto dopaminergic neurons in ventral tegmental area: role of $\mu$-opioid receptors. Neuoscience 153: 240-248.

Yan QS, Zheng SZ, Feng MJ, Yan SE (2005). Involvement of 5 -HT1B receptors within the ventral tegmental area in ethanolinduced increases in mesolimbic dopaminergic transmission. Brain Res 1060: 126-137.

Ye JH, Wang F, Krnjevic K, Wang W, Xiong ZG, Zhang J (2004). Presynaptic glycine receptors on GABAergic terminals facilitate discharge of dopaminergic neurons in ventral tegmental area. J Neurosci 24: 8961-8974.

Ye JH, Zhang J, Xiao C, Kong JQ (2006). Patch-clamp studies in the CNS illustrate a simple new method for obtaining viable neurons in rat brain slices: glycerol replacement of $\mathrm{NaCl}$ protects $\mathrm{CNS}$ neurons. J Neurosci Methods 158: 251-259.

Zheng F, Johnson SW (2003). Metabotropic glutamate and muscarinic cholinergic receptor-mediated preferential inhibition of $\mathrm{N}$-methyl-D-aspartate component of transmissions in rat ventral tegmental area. Neuroscience 116: 1013-1020.

Zhu W, Bie B, Pan ZZ (2007). Involvement of non-NMDA glutamate receptors in central amygdala in synaptic actions of ethanol and ethanol-induced reward behavior. J Neurosci 27: 289-298. 